\title{
Proceso de producción de una teoría lingüística y semiológica $^{1}$
}

\author{
Production process of a linguistic and semiological theory
}

Ana María Nethol

Una ojeada a la ciencia del lenguaje permite observar que ésta se reconoce como tal en un proceso teórico operativo que, manejando las lenguasnaturales, instaura modelos de análisis de sistemas significantes (lingüísticos) a partir de un primer; deslinde de campos o niveles de estudio (fonológico, morfológico, sintáctico, léxico). En esta delimitación que realiza la lingüística para describir la lengua operan fundamentalmente dos perspectivas de análisis: el estudio de la organización de las unidades sobre la base de sus relaciones sistemáticas de oposición (paradigmático) y el de las reglas de combinación de dichas unidades en las frases y el discurso (sintagmático). Se establecen así los mecanismos que subyacen a la utilización del lenguaje por los individuos. Se constituyen sistemas de representaciones lingüísticas que varían de una escuela a otra, pero que tienen como rasgo común el pasaje de lo sustancial y manifiesto, a las estructuras que se delimitan a partir del sistema a que pertenecen. Posteriormente, y coincidiendo Con nuevos, avances teóricos de la lingüística, se produce un desplazamiento científico: muchas ciencias sociales integran los aportes de la lingüística $\mathrm{y}$, en una nueva perspectiva, comienzan a interpretarse a partir -de las relaciones significantes de su objeto. Estos diversos campos -sociológico, antropológico, psicoanalítico, literario, etc.-, se consideran series estructuradas como lenguajes, emparentadas con los modelos originados en las lenguas naturales, pero practicando a su vez un enfoque translingüístico, que implica un manejo de elementos que difieren de los propiamente lingüísticos en un doble plano cuantitativo-cualitativo. La diferencia cuantitativa se establece en relación con el análisis trans-lingüístico que opera (o puede, operar) con unidades que rebasan en extensión las unidades mínimas delimitadas en el análisis de las lenguas naturales; así, una unidad o función en determinado tipo de discurso literario (Propp) o una forma mínima del mito puede no coincidir con la unidad frase o sintagma que determina el análisis lingüístico. El plano cualitativo supone un "desborde" más amplio del marco de representaciones que se vinculan con las lenguas naturales: se trata de análisis de lenguajes o sistemas diferentes (de gestos, de imágenes, de objetos) que recurren a los modelos lingüísticos para describir sistemas cualitativamente distintos. En este sentido podríamos hablar de una adopción, de una especie de punto de partida semiológico que, hacia la década de 1950, desarrollan algunas ciencias sociales y algunas tendencias dentro de esas ciencias, para modelar su objeto de estudio; esta adopción no dejaba de tener sus peligros: el tratamiento de los fenómenos culturales como sistemas de signos implicó en los países centrales un intento de constitución de las ciencias humanas "a imagen y semejanza" de los modelos de análisis planteados por la lingüística con el consecuente distanciamiento entre el sujeto de conocimiento y su objeto y la distorsión de los objetos específicos de dichas ciencias y de la lingüística misma. A este respecto abundaron acaloradas discusiones entre partidarios y detractores del semiologismo (derivado de la utilización de modelos estructurales). Mientras

1 Tomado del libro Ferdinand de Saussure. Fuentes manuscritas y estudios críticos, 1977, edición a cargo de Ana María Nethol. El texto encabeza la segunda parte, 'estudios críticos', pp. 105-114 [Nota del editor]. 
los primeros exaltaban el valor intrínsecamente semiológico de los fenómenos que abordaban, los segundos, con razón, criticaban la a-historicidad y formalismo que proponía el modelo estructural tal como era retomado por esas ciencias, o por ciertos discursos de esas ciencias, al considerar que se enfrentaban con dos posiciones coincidentes en su principio: la perspectiva de análisis desde el materialismo histórico y la vinculación dialéctica entre sujeto y objeto de la ciencia con las consecuencias teóricas, empíricas y tecnológicas que acarreaba.

No quiero insistir en esta problemática; mi intención es tan solo mencionarla para esclarecer parcialmente una zona aún bastante oscura en el tratamiento de las ciencias humanas y ubicar allí, como objetivo fundamental, el papel que juega la teoría de Ferdinand de Saussure.

De todas maneras, quisiera plantear, ya a distancia temporal de las discusiones, una instancia superadora, o conciliadora, si se quiere: la posición de clase y el contexto social producirían (producen) las condiciones básicas de la actividad científica, que permiten la pluralidad de abordajes de un objeto en función de una teoría explicativa a través de diversas prácticas, donde se incluye la semiológica como uno de los niveles de comprensión de la realidad en aquellos casos en que la necesidad empíricoideológica lo requiera. Por otra parte, podemos hablar de una existencia más o menos autónoma de los estudios semiológicos que se han centrado, justamente en las dos últimas décadas en una tarea bastante homogénea de desmitificación de los discursos de los sistemas vigentes en países dominantes y dependientes; esto equivale a decir que la semiología, independientemente de las consideraciones que podamos hacer sobre su origen epistemológico, puede ser utilizada como cuerpo teórico-operativo, como material instrumental para un proyecto amplio de conocimiento y transformación de la realidad que manipula, partiendo del supuesto de que el sujeto es protagonista del proceso en el que está inmerso y que, a su vez, el análisis de los discursos y su significación, se sitúe en el campo en que se sitúe, sólo puede interpretarse a partir de las condiciones históricas y políticas de las que emerge.

En este proceso que va de la constitución de da lingüística como ciencia al desarrollo de la semiología (tanto en el desplazamiento que operan algunas ciencias sociales como en el estudio autónomo del campo, o bien en la constitución del material instrumental a que acabo de hacer referencia), el discurso de Saussure no sólo abre la profunda brecha que separa a la lingüística de su estadio precientífico sino que señala además el camino a los posteriores trabajos semiológicos, ubicando a la lingüística como caso particular en relación de pertenencia a un campo más general y abarcador: la ciencia que se ocupa de los sistemas de signos. Uno de nuestros propósitos es demostrar en este breve trabajo que todos los pasos de su discurso se van concretando a partir de esta doble formulación lingüístico-semiológica. Como afirma Greimas, "1as metáforas de Saussure que siguen impactando nuestra imaginación son todas extra-lingüísticas: el juego de ajedrez, el anverso y reverso de la hoja de papel, el tren de París; la descripción de las lenguas naturales es para él sólo una tarea particular situada en el interior de la semiología".

La innovación de Saussure, por otra parte, consiste principalmente en descartar al objeto como "hecho" y en constituirlo en función de reflexión para reconocerlo y delimitarlo. Esta preocupación se centra en la especificación del concepto de lengua, con la consecuente búsqueda de su definición de las propiedades que lo constituyen. Todo el esfuerzo de su obra, especialmente todo el esfuerzo de conocimiento, se ubica en esta búsqueda. Es el soporte temático, el contenido global que guía sus especulaciones y ordena su discurso a pesar de las aparentes contradicciones en que incurre a través de los tres cursos que dicta en la Universidad de Ginebra.

Esta determinación de la noción de lengua, este trabajo para constituirla y cuyo proceso puede verse con claridad en el texto de la 
Introducción que precede a este artículo ${ }^{2}$, apoyada permanentemente por el fundamento que le proporciona la ubicación semiológica, se manifiesta en Saussure como un proceso de sucesivas exclusiones de los elementos que no entran en sus propiedades internas.

La primera operación de "descarte" tiende a deslindar la materia específica de la lingüística a fin de superar el obstáculo constituido por una serie de entrecruzamientos con ciencias conexas que habían incidido fuertemente en las especulaciones lingüísticas anteriores. Con esto apunta también a la reivindicación de un objeto específico que no se confunda con el de otras ciencias y que supone la exclusión de los posibles elementos (antropológicos, fisiológicos, psicológicos, filológicos, etc.) de otras disciplinas que puedan alojarse en el tratamiento del fenómeno lingüístico.

La confrontación del Curso de Lingüística General con los apuntes tomados en clase por los alumnos [...] aporta datos importantes sobre esta operación. En el Curso, los compiladores descartan las ciencias conexas e insisten fundamentalmente en las tareas que tiene que realizar la lingüística, sin especificar dentro de qué encuadre epistemológico se ubica ni cuál es su identidad respecto de otros campos de conocimiento. Sin embargo, este problema de identidad de la ciencia aparece resuelto en los siguientes párrafos:

Para asignar un lugar a la lingüística, no es necesario tomar la lengua en todos sus aspectos. De esta manera, muchas ciencias (psicología, fisiología, antropología, gramática, filología, etc.) podrían reivindicarla como su objeto. Toda vía analítica no nos conduce a nada. Seguiremos una vía sintética. Tenemos que tomar lo que sentimos como esencial y entonces podremos asignarle al resto su verdadero lugar en la lengua. ¿Es muy difícil? Ante todo, la lengua es un sistema de signos y es necesario recurrir a la ciencia de los signos que nos permite reconocer en qué consisten sus leyes, etc. Esta ciencia no existe en las disciplinas conocidas; se trataría de una semiología (ninguna relación con la semántica: ciencia del sentido de las palabras por oposición a la de las formas). Es evidente que la lengua no abarca todos los tipos de signos. Debe existir entonces una ciencia de los signos más amplia que la linguistica (sistemas de signos: marítimos, de ciegos, de sordomudos y finalmente, lo más importante: ¡de la escritura misma!).

Como puede verificarse en la Introducción, este texto pertenece a la clase de Saussure dictada el 12 de noviembre de 1908, apenas comenzado el segundo curso. Consiste en una exposición que puede segmentarse en dos subunidades: la primera, de descarte y la segunda, de encuadre; esta secuencia permite, por una parte, la confrontación con la omisión que hacen los editores del Curso, cuando eluden ocuparse de la semiología y la interpretación errónea que de allí puede desprenderse en la medida en que se ignora en función de qué elementos Saussure recorta su afirmación, tema que despachan en pocas líneas (dos páginas y media) sin volver a ocuparse de él ni mencionarlo en el resto del libro (véase p. 59 y ss. Curso de Lingüística General, Buenos Aires, Losada, 19453). En la segunda parte del fragmento es clara la apoyatura de Saussure en la aproximación lingüístico-semiológica, es decir, en la ruptura de relación con otras ciencias para la definición de la lingüística a fin de encontrar las alianzas epistemológicas de su objeto con series posibles de sistemas unificados por una ciencia general que los abarque.

Por otra parte, este fragmento posee una significativa afirmación: la de la inclusión de la escritura como uno de los posibles campos de estudio que corresponderían a esta ciencia general; esta mención que, de acuerdo con la versión de los alumnos, Saussure expresa enfáticamente considerándola como "lo más importante", es también omitida en la confección del Curso, tanto en el capítulo mencionado antes como en el que se refiere a la escritura (véase

2 La autora se refiere a la primera parte del libro citado en la nota 1 en donde se presentan los apuntes de la Introducción compilados y ordenados por Robert Godel y publicados inicialmente en la revista Cahiers Ferdinand de Saussure en 1957. Dicha Introducción fue traducida al español para la edición de 1977 y comprende las páginas 19-101 [Nota del editor].

3 La edición de Amado Alonso, esto es, la primera traducción al español [Nota del editor]. 
Curso... p. 71 y ss.). Destaquemos entonces por el momento que, en el marco de esta afirmación, la escritura constituiría para Saussure un sistema de signos particular cuyo campo específico sería tratado por la ciencia semiológica.

Sin embargo, en un segundo procedimiento de descarte, luego de haber obtenido un primer camino inductivo hacia el objeto, en nombre de la delimitación de la lingüística, excluye a la escritura de su campo (véase Introducción, p. 24 y ss., y Curso, p. 79). Este procedimiento, mal interpretado por autores que se remiten exclusivamente al Curso, y que además construyen un aparato teórico donde la escritura es considerada como principio fundante del acto lingüístico (véase Jacques Derrida, De la gramaticología, Buenos Aires, Siglo XXI, 1971, p. 37 y ss.) y aceptado acríticamente por otros, en particular sus discípulos de la Escuela de Ginebra constituye una aparente contradicción que conviene aclarar en qué condiciones se produce y cuáles son las causas que lo determinan. No es necesario alejarse demasiado de las fuentes saussureanas para encontrar las razones: las condiciones de este descarte se producen por el obstáculo que constituían los trabajos anteriores y/o contemporáneos a Saussure, quien, es preciso recordarlo, pertenecía a la etapa filológica, al momento de prevalencia de los estudios histórico-comparativos de los fenómenos del lenguaje.

Este tipo de estudios podemos imaginarlos como un espacio cuadriculado donde las líneas verticales indicarían la evolución de las palabras y sonidos en el tiempo y las horizontales las relaciones de éstos con otros de diferentes lenguas, en un camino diacrónico que marchaba de las formaciones contemporáneas a las anteriores, y viceversa, en busca de unidades últimas que remitieran al origen del fenómeno, ateniéndose a su linearidad temporal para señalar su evolución en el tiempo y leyes generales de transformación. Por otra parte, y como consecuencia de la continuidad temporal del fenómeno estudiado, los métodos operaban fundamentalmente sobre la descripción de los cambios sucesivos de la sustancia: descripción de evoluciones fonéticas retomadas a partir de documentos escritos sin tener en cuenta, para hablar desde una perspectiva saussureana, la evolución de la forma que subyace en esas manifestaciones sonoras si es que de ello puede hablarse tratándose del manejo casi exclusivo de la comparación de textos proporcionados por la escritura.

Esta noción de forma, una de las vertientes fundamentales de la problemática de Saussure, indica en su discurso el sistema de relaciones y oposiciones que sostienen entre sí las unidades lingüísticas en un momento dado, en un estadio puntual de la evolución, concepto que puede vincularse al plano de las transformaciones diacrónicas, siempre que se tengan en cuenta los cambios que afectan a la totalidad del sistema que se producen de un estadio a otro de la evolución en el tiempo y no en el mero cambio de la sustancia fónica (así como de los mecanismos sintácticos, de la evolución léxicosemántica de las unidades, etc.). Saussure es consciente de la limitación científica que supone un abordaje de tal naturaleza, pero, además, llega a prevenir de las derivaciones históricas que puede arrastrar, no sólo por su influencia sobre los estudios del lenguaje, sino también por la presión que el lenguaje escrito puede ejercer sobre el habla. Volvamos a la Introducción: la preocupación de Saussure por este aspecto resalta con mucha más intensidad que en el Curso:

La lengua y la escritura. Pareciera que una y otra fueran solidarias; sin embargo, es necesario distinguir radicalmente entre ellas. Sólo la palabra hablada es objeto de la lingüística.

La clasificación de la lengua en el tiempo sólo es posible porque la lengua se escribe. No se puede entonces rechazar la importancia de la escritura.

En efecto, además de señalar un estadio de la civilización y perfeccionamiento en el empleo del lenguaje, la lengua escrita y la escritura repercuten sobre la lengua hablada.

No se observa nada de anormal en las lenguas no escritas, sino lo contrario. 
Una lengua que no ha sido jamás escrita constituye su norma.

Pero las influencias de la lengua escrita sobre la hablada son múltiples: uno se ve obligado a cierta elección, se conservan sólo las palabras que se escriben a menudo, se vicia la pronunciación (sept cents, Lefevure por Lefèvre).

La lengua escrita y la lengua hablada: un aspecto más de las correspondencias de la lengua, uno de sus costados dobles; en la correspondencia existe una dualidad en los sistemas de signos. Y esta correspondencia varía con las escrituras (china y latina, por ejemplo). La correspondencia no es perfecta: existen casos en los que la palabra escrita no representa la palabra hablada.

Esta correspondencia ha producido y produce aún efectos deplorables. Nunca es totalmente posible deshacerse de la palabra escrita.......

Cuando la escritura se vuelve corriente, se crea un tipo de lengua escrita que constituye la norma y que no puede ser ignorada frente a los dialectos locales".

El fragmento que transcribo demuestra que tanto la sobrevaloración como el desinterés por la escritura constituyen para Saussure un peligro que sobrepasa sus preocupaciones estrictamente lingüísticas. El prestigio de la escritura constituye una fuente de dominio cultural que no desconoce. Este señalamiento es muy importante: quienes desde diversos campos vinculados a la ciencia del lenguaje nos hemos acercado a observar las particularidades de los fenómenos del habla, reconocemos hasta qué punto la norma, que toma como punto de partida la fijeza de la escritura, actúa como factor externo de prescripción y poder sobre las tendencias del habla.

Por otra parte, también es claro para Saussure que el estudio diacrónico basado en fuentes escritas perdía de vista los límites entre sonido y letra: "ni el mismo Bopp- afirma-hace distinción clara entre sonido y letra; al leerlo se creería que una lengua es inseparable de su alfabeto; sus sucesores inmediatos cayeron en la misma trampa". (Curso, p. 73.)
Para poder ubicar más precisamente esta operación de descarte, sintetizamos los aspectos que la fundamentan:

1) El estudio diacrónico, que tiene como fuente los textos escritos, representa un análisis del cambio lingüístico sobre la base de las modificaciones de la sustancia, en detrimento de las modificaciones entre términos que afectan la totalidad del sistema en un momento dado de la evolución.

2) La manipulación del lenguaje escrito como fuente de análisis supone un alto grado de confusión entre la letra y el sonido: esta confusión distorsiona y superpone objetos científicos de naturaleza heterogénea.

3) La distorsión afecta, no solamente las posibilidades de análisis, sino también la tendencia del lenguaje oral, por cuanto en función de la escritura se dictaminan normas que actúan como violencia y censura.

En esta síntesis pueden determinarse dos tipos bien definidos de obstáculos que Saussure tiene que superar para continuar la elaboración de su objeto. Como vimos, el primero se sitúa en la relación sustancia-forma. Bajo esta perspectiva, en su concepción, escritura se opone a lengua por ser la primera una manifestación, y la segunda, el mecanismo subyacente que la determina. El segundo obstáculo se ubica por una parte, en la situación de indiscriminación científica y metodológica entre objetos de diferente naturaleza y por otra, en los mecanismos de presión que, desde la práctica lingüística se obligaba a ejercer a la escritura .sobre el lenguaje hablado. Así como la primera dificultad se situaba en la relación sustancia-forma o bien lengua-escritura, la segunda se sitúa en una oposición de carácter bien diferente: la relación escritura-habla.

Este último obstáculo conduce a Saussure a la siguiente afirmación: "sólo la lengua hablada es objeto de la lingüística". De este modo afirma en el mismo movimientola autonomía de ambos sistemas para diluir los errores de entrecruzamiento en que habían caído sus predecesores y contemporáneos y la necesidad de desprendimiento del poder normativo de la escritura. 
Para seguir adelante y comprender mejor este proceso de conocimiento, retomemos el punto 1) de la síntesis antes propuesta: los textos escritos como fuente del estudio diacrónico. Este aspecto contribuye decisivamente al descarte de la escritura, no por la escritura misma en tanto objeto semiológico, sino por presentarse como el vehículo desde donde parten los estudios diacrónicos, ubicados por él, según dijimos, en el mero cambio de sustancia. Este descarte permite entonces una nueva delimitación que lo proyecta hacia su objeto: destaca. la distancia que media entre la manifestación y la estructura, entre el fenómeno y su organización semiológica, entre el estudio diacrónico y el sistema de la lengua.

Enestadiferenciadenivel,eldelamanifestación por una parte y el de la organización semiológica por otra, se inserta la tercera operación de descarte, que lo lleva a sostener la famosa dicotomía lengua-habla. El habla es definida en relación con la lengua como su contracara individual: ejecución del acto fónico concreto determinado por la naturaleza semiológica de la lengua. Así el habla, como apropiación individual del sujeto hablante y continuo fisiológico, participa también, como la escritura, del dominio de la sustancia, mientras la lengua constituye un sistema de valores cuyo "medio de producción es indiferente".

¿Qué queda entonces como "marca" que define las características de la lengua en el marco de este proceso teórico? Una vez extraídos y descartados aquellos elementos que hacen al hecho concreto de la manifestación, las confusiones teóricas entre niveles y la participación de otras ciencias en el campo de los estudios lingüísticos, sólo se mantiene como hecho de lengua el carácter social y ubicación como sistema de signos cuyos mecanismos se describen en el Curso. Pero estos rasgos no indican de por sí la naturaleza estrictamente lingüística del objeto que se delimita: lo que ocurre es que la noción de lengua, tal corno es elaborada por Saussure va mucho más allá de la lingüística: se presenta como noción abarcadora de todo sistema significativo.

Por otra parte, esta ubicación de la lengua se reproduce también en relación con las unidades (signos) que la constituyen: en lo que va del primero al tercer curso comienza a identificar dichas unidades sobre tanteos que parten de un estricto campo lingüístico.

En una primera instancia, presenta al signo como dualidad sílabas-significación, más adelante como sonido-concepto. ¿Por qué entonces, si poseía una nomenclatura lingüística que explicitara la dualidad del signo, opta por la nomenclatura significante-significado? Una vez más se presenta una exclusión significativa: Saussure se sitúa frente al signo en la misma dirección que implicaba la noción de lengua; la división significante-significado, que recién establece al final del tercer curso, alcanza tanto a las unidades lingüísticas como a las de cualquier otro campo semiológico.

Es así corno en cada eslabón de su proceso teórico marcha sobre esta doble relación lingüístico-semiológica; esto confirma y explicita algunas de las observaciones que aparecen al comienzo de este artículo: en primer lugar, sus planteos marcan una nueva perspectiva para la lingüística en la medida en que establece los mecanismos fundamentales del lenguaje humano y formula una teoría general de la lengua; por otra parte, inaugura una nueva forma de trabajo para reconocer el comportamiento de otros sistemas significativos, sobre la base de su carácter social y sistemático. 